\title{
Administração, gestão e políticas públicas: interfaces e diálogos com o campo organizacional
}

\author{
Profa. Dra. Alketa PeCl ${ }^{1}$ \\ Prof. Dr. Hélio Arthur ReIS IRIGARAY ${ }^{1}$ \\ PROF. DR. FABRICIO STOCKER ${ }^{2}$ \\ ${ }^{1}$ Fundação Getulio Vargas (FGV EBAPE) / Escola Brasileira de AdMinistração Pública e de EMPRESAS, RIO de JANEIRO - RJ, BRASIL \\ 2 Fundação Getulio VARgas (FGV) / CADERNos EBAPE.BR, RIO DE JANEIRO - RJ, BRASIL
}

\begin{abstract}
O campo da administração e da gestão públicas tem por interesse atuar na prestação dos serviços governamentais, gerenciando programas e estimulando a implementação de políticas na área, tendo como responsáveis e interessados, em sua grande maioria, administradores, formuladores de políticas, populações constituintes e toda a sociedade, em nível local, estadual, nacional ou internacional. A discussão e a interlocução entre sistema político, modernização do Estado, gestão pública e o reflexo desses diferentes elementos no campo organizacional são, no mínimo, complexas e muito oportunas.
\end{abstract}

Para esta edição temática em administração pública, temos como convidada especial a Profa. Dra. Alketa Peci, diretora-presidente da Associação Nacional de Pós-Graduação e Pesquisa em Administração (Anpad) e editora-chefe da Revista de Administração Pública (RAP) da FGV EBAPE, que nos apresenta as interfaces e os diálogos necessários entre os estudos de administração e gestão pública e o campo organizacional, escopo editorial condutor dos Cadernos EBAPE.BR.

Administração pública é o governo em ação, resumia Wodrow Wilson há mais de 100 anos. Até hoje, essa definição ressoa como uma concepção pragmática e dialética de uma burocracia publica imersa na sociedade moderna. Entretanto, a administração pública se transforma, na medida em que se modifica o próprio papel do Estado. Consequentemente, mudam as relações que o setor público estabelece com a política, o mercado e a sociedade civil, assim como a forma de agir do setor público, dos gestores públicos e dos burocratas. Neste breve texto, busco refletir sobre mudanças estruturais, conjunturais, e os desafios que elas representam para os pesquisadores deste campo rico, multidisciplinar e multifacetado denominado administração pública.

Há décadas, e não apenas no Brasil, o modelo "ideal” da burocracia weberiana é desafiado por novos modelos igualmente ideais de mercado e de rede. A burocracia weberiana se assenta na autoridade racional-legal, buscando a eficiência administrativa, mas garantindo os preceitos democráticos via democracia representativa. Políticos democraticamente eleitos delegam a gestão pública para técnicos profissionais (burocratas), que buscam otimizar a eficiência e a produtividade, observando princípios como impessoalismo e universalização.

Ao contrário do que, de maneira ambígua, se preconiza em movimentos como o new public management, o modelo ideal de mercado busca incentivar a competição entre os órgãos públicos e entre o público e o privado, porque enxerga na escolha resultante dessa competição o melhor princípio democrático e de gestão.

Por fim, o modelo de rede se assenta no princípio democrático de participação direta e da colaboração, promovendo a governança colaborativa (ou contratual) com atores diversos, com ou sem fins lucrativos, e com a cidadania. Se, por um lado, esses atores são considerados indispensáveis no processo de elaboração e implementação de políticas públicas, por outro, modifica-se o papel do Estado, que passa a ser coordenador, articulador ou regulador dessa complexa rede de atores políticos.

Desde o governo Vargas até os anos 1980, as burocracias públicas foram, em boa parte, atores responsáveis pela formulação, pela implementação e pelo controle de políticas públicas, gerando disfunções, mas também acumulando expertise e conhecimento. A expansão da burocracia refletiu o projeto desenvolvimentista do Estado brasileiro, diferentemente do progressivismo norte-americano ou do bem-estar social europeu. Como consequência, o modelo das brás, a grande empresa estatal, predominante em vários setores econômicos e industriais, foi o dominante, gerando grandes desigualdades regionais e a expansão da tecnocracia. 
A crise do Estado e os processos de liberalização econômica e democratização transforam o papel da administração pública. Ao longo das últimas décadas, o Estado brasileiro deixou de ser provedor direto em importantes setores econômicos, sociais, e passou a contar com a participação de empresas privadas e/ou organizações do terceiro setor na implementação de várias políticas públicas. Surgiu um conjunto de agências reguladoras de natureza independente que regula complexas relações contratuais com empresas privadas. Ao mesmo tempo, um número crescente de organizações sociais (OS), organizações da sociedade civil de interesse público (Oscips) e instituições da sociedade civil passaram a implementar políticas sociais em áreas como saúde, ciência e tecnologia, assistência social, entre outros, contando, quase exclusivamente, com financiamento público, que cresceu muito ao longo de governos de orientação mais social.

Hoje, o campo da administração pública brasileira é marcado por instituições sincréticas, inspiradas nos ideais de burocracia, mercado ou rede, e marcadas por resquícios do passado, mas também por inovações em dimensões inesperadas, como orientação de decisões baseadas em evidências ou capilaridade de participação. Essas lógicas institucionais orientam a ação dos atores políticos no campo. Entretanto, a virada do século encontra o Estado brasileiro em ação com um projeto ainda não esgotado de universalização de serviços públicos e uma grande pressão social para maior inclusão e bem-estar coletivo, refletindo os preceitos da Constituição cidadã.

Embora a estrutura de provisão da ação estatal tenha se modificado em sua essência, passando de burocracias hierarquizadas para complexas redes contratuais, a burocracia que agora deveria ser responsável por planejar, implementar e monitorar contratos continua a operar nos mesmos moldes da hierarquia centralizadora. De modo concreto, isso significa um foco em processos, documentos, certificados e notas fiscais - elementos formais que não ajudam a desvendar a verdadeira natureza do mercado com o qual se coopera/contratualiza. Ainda que a desconfiança reine, falta experiência para revelar os cartéis que dominam vários setores de compras públicas, de modo a verificar que boa parte das ONGs que recebem repassem públicos tem, entre seus sócios-fundadores, políticos ou servidores públicos - passo necessário, porém insuficiente para quebrar o elo entre contratos do setor público e políticos.

A administração pública se torna refém das próprias ineficiências no âmbito administrativo - especificamente nas atividades de planejamento, implementação e monitoramento -, as quais abrem espaço para a ação discricionária dos órgãos de controle, que hoje tem demonstrado maior competência para compreender a complexidade das relações acima citadas. Reina o "apagão de canetas" no momento em que a sociedade demanda mais o governo em ação.

Os desafios acima destacados se refletem na crise reputacional que hoje marca o setor público no Brasil e nos índices baixíssimos de confiança no governo (Latinobarómetro, 2021). Sem dúvida, a cobertura midiática negativa, exacerbada pela centralidade das denúncias de corrupção associadas à Lava-Jato, agrava a imagem do setor público perante a população (Peci, 2021), mas não explica a crise de legitimidade da burocracia. Adicionem-se a esse cenário, já desafiador, as ameaças advindas da polarização política e dos riscos impostos por governos de natureza populista e autoritária que privilegiam a lealdade em vez do profissionalismo burocrático, como uma extensa pesquisa de campo sobre populismo e ameaças democráticas parece indicar (Dussauge-Laguna \& Aguilar, 2017; Peters \& Pierre, 2019; Moynihan \& Roberts, 2021).

Paradoxalmente, a pandemia da COVID-19 evidenciou o papel central da gestão pública e de uma burocracia profissional, que precisa resgatar mecanismos de autonomia decisória, fortalecer-se num ambiente de cooperação e coordenação federativa, além de passar por mudanças qualitativas que eliminem distorções burocráticas e favoreçam sua legitimidade e seu poder de ação (Peci \& Teixeira, 2021). Compreender as lógicas que dominam o campo da gestão pública contemporânea e orientam sua ação demanda o esforço e a reflexão coletiva de muitos pesquisadores que trabalham na interface da administração e da gestão públicas, bem como no campo organizacional.

Com este editorial temático de administração pública, delimitamos um novo ciclo, em que os Cadernos EBAPE.BR retomam seu direcionamento para estudos voltados à discussão do campo organizacional, privilegiando o debate e a pluralidade de ontologias, epistemologias, metodologias e abordagens teóricas nos estudos organizacionais, convidando autores e pesquisadores da área de administração, gestão e políticas públicas a dialogarem com as demais revistas científicas da área, como a RAP, da FGV EBAPE, e os Cadernos de Gestão Pública e Cidadania (CGPC), da FGV EAESP.

Iniciamos esta edição temática dos Cadernos EBAPE.BR com a discussão sobre "Gestão social e desenvolvimento comunitário: o poder da organização informal em empreendimentos habitacionais de interesse social", escrita por Suzana Melissa de Moura Mafra da Silva e Washington José de Souza, que nos apresentam a qualidade do diálogo e das relações intersubjetivas que contribuem para apontar iniciativas emancipatórias e revelar melhorias na vida comunitária. 
Já Carlos Augusto Alves de Sousa Júnior e Diego Costa Mendes, em "Políticas públicas para a população LGBT: uma revisão de estudos sobre o tema", identificam os principais pontos apresentados como entraves às políticas públicas LGBT no Brasil, como inexistência de leis que resguardem os direitos dessa população, falhas na interlocução entre Estado e sociedade civil, falta de previsão orçamentária para planos e programas, além de ausência de representação política.

O terceiro artigo, "Dinâmicas da agenda do aborto no Senado Federal: de 1988 a outubro de 2020", escrito por Maria Clara Figueiredo Dalla Costa Ames, Mauricio Custódio Serafim, Marcello Beckert Zappellini e Andrei Costa Colonetti, apresenta, por meio de pesquisa documental e análise de conteúdo, os resultados de 33 proposições legislativas, 295 pronunciamentos e 6 audiências públicas, contribuindo para uma agenda de pesquisas futuras.

Por sua vez, Marcos Caldeira e Simone Cristina Dufloth, em "A lei das estatais e as diretrizes internacionais: convergências para o estado da arte em integridade, compliance e anticorrupção", investigam a convergência dessas 3 diretrizes introduzidas pela Lei das Estatais, em face das melhores práticas internacionais, sinalizando, ao fim, uma agenda de estudos aplicados, devotada a investigar e compreender os desafios da implementação da lei e seus resultados concretos no universo das companhias estatais.

Visando validar um modelo derivado de abordagens teóricas para mensurar as capacidades do Estado, especificamente do governo federal brasileiro, Alexandre de Ávila Gomide, Raphael Amorim Machado e Pedro Melo Albuquerque nos apresentam o artigo "Capacidade estatal e desempenho na percepção dos burocratas brasileiros: desenvolvimento e validação de um modelo de equações estruturais".

Em "A formação da previdência no contexto da seguridade social: uma análise da policy agenda-setting", Raquel Andrade Silva de Oliveira, Bruno Tavares, Thiago de Melo Teixeira da Costa e Suely de Fátima Ramos Silveira analisam, por meio da teoria dos múltiplos fluxos, como a previdência se tornou um elemento da seguridade no âmbito das políticas públicas na Constituição Federal de 1988.

Ellysson Fernandes Rosa, Estela Najberg, Lauren de Lacerda Nunes e João Luiz Passador, por sua vez, em "Como a filosofia pode iluminar a gestão pública em tempos de polarização política", ensaiam uma contribuição para as naturezas que compõem a estrutura do conhecimento aplicado à administração pública e a separação entre o institucional e o privado.

A revisão da literatura científica e de documentos oficiais publicados por órgãos governamentais brasileiros e internacionais de saúde, visando obter dados relacionadas com a organização de sistemas de saúde, frente a emergências em saúde pública, foi o objeto de estudo de Adriano Massuda, Ana Maria Malik, Gonzalo Vecina Neto, Renato Tasca e Walter Cintra Ferreira Junior, em "A resiliência do Sistema Único de Saúde frente à COVID-19".

Em "Resiliência nos valores públicos e sua permanência: uma análise dos contratos administrativos no Brasil", Fernanda Alves Andrade Guarido, Eloy Eros da Silva Nogueira e Mayla Cristina Costa Maroni Saraiva refletem, sob um viés sociológico, os valores públicos e os padrões normativos e culturais da sociedade, analisando os modelos de gestão da administração pública brasileira.

Adauto de Vasconcelos Montenegro, Ana Paula Moreno Pinho, Antonio Caubi Ribeiro Tupinambá e Raquel Libório Feitosa em "É possível encontrar inovação gerencial e práticas de gestão de pessoas voltadas à inovação em universidades federais?", discutem sobre a inovação gerencial e as práticas de gestão de pessoas voltadas à inovação em 2 universidades federais.

O artigo "Complexidade institucional no campo esportivo de Santos após implantação do Promifae", escrito por Donald Veronico Alves da Silva e Patricia Maria E. Mendonça, demonstra que a implementação do programa revela ambiguidades e conflitos de lógicas institucionais já existentes no campo esportivo, ampliando o alcance da lógica de mercado.

"Serviços de governo eletrônico no Brasil: uma análise sobre fatores de impacto na decisão de uso do cidadão", escrito por Luiz Claudio Mendes Vargas, Marie Anne Macadar, Peter Fernandes Wanke e Jorge Junio Moreira Antunes, trata dos fatores que influenciam a utilização de serviços de governo eletrônico pelos cidadãos, tendo por objetivo avaliar se aspectos sociodemográficos têm influência sobre tal decisão.

Por fim, Geraldo Tessarini Junior e Patrícia Saltorato discutem as experiências e as percepções de servidores públicos técnicoadministrativos em relação à organização de seu trabalho, em "Organização do trabalho dos servidores técnico-administrativos em uma instituição federal de ensino: uma abordagem sobre carreira, tarefas e relações interpessoais".

Boa leitura a todos!

Profa. Dra. Alketa Pecl

Prof. Dr. Hélio Arthur Reis Irigaray

Prof. DR. FABRICIO STOCKER 


\section{REFERÊNCIAS}

Dussauge-Laguna, M. I., \& Aguilar, M. (2021). Populismo, retrocesos democráticos y administraciones públicas: la experiencia de México durante el gobierno de Andrés Manuel López Obrador. Estado, Gobierno, Gestión Publica, 36, 135-186.

Latinobarómetro. (2021). Informe Latinobarómetro 2021. Recuperado de https://www.latinobarometro.org/lat.jsp

Moynihan, D., \& Roberts, A. (2021). Dysfunction by design: trumpism as administrative doctrine. Public Administration Review, 81(1), 152-156.
Müller, J. W. (2017). Populism and constitutionalism. In C. R. Kaltwasser, P. Taggart, P. O. Espejo, \& P. Ostiguy (Eds.), The Oxford handbook of populism. Oxford, UK: Oxford University Press.

Peci, A. (2021). Agencies in the news? Public agencies' media evaluations in a low-trust context. Governance, 34(4), 1075-1095.

Peci, A., \& Teixeira, M. A. C. (2021). Desafios da administração pública brasileira. GV Executivo, 20(1), 37-39.

Peters, B. G., \& Pierre, J. 2019. Populism and public administration: confronting the administrative state. Administration \& Society, 51(10), 1521-1545.

Profa. Dra. Alketa Peci

ORCID: https://orcid.org/0000-0002-0488-1744

Doutora em Administração; Professora associada da Escola Brasileira de Administração Pública e de Empresas da Fundação Getulio Vargas (FGV EBAPE); Editora-chefe da Revista de Administração Pública (RAP). E-mail: alketa.peci@fgv.br

Doutor e Mestre em Administração de Empresas pela FGV EAESP e PUC-Rio, respectivamente; Bacharel em Economia pela University of Northern lowa, EUA; Professor adjunto da FGV EBAPE e do programa CIM - Corporate International Masters, da Georgetown University, Washington, EUA; Líder do tema Diversidade e Relações de Trabalho, na linha de Gestão de Trabalho (ANPAD). E-mail: helio.irigaray@fgv.br

Prof. Dr. Fabricio Stocker ORCID: https://orcid.org/0000-0001-6340-9127

Doutor em Administração pela FEA/USP e Ph.D. in Management pela Erasmus University of Rotterdam; Pesquisador visitante na University of Amsterdam; Mestre em Administração pela UFPR e formação executiva pela FGV pela London Business School; Economista e Administrador; Professor na FGV na graduação on-line, MBA e Pós-Graduação; Atua como Editor Adjunto no Cadernos EBAPE.BR (FGV). E-mail: fabricio.stocker@fgv.br 